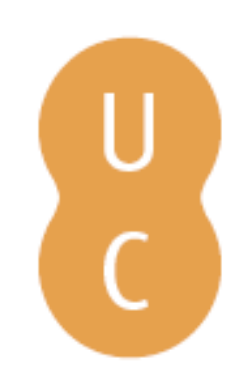

\title{
nommalina
}

\section{A abordagem fenomenológica de Heidegger ao conceito de vida e o começo da biopolítica}

\author{
Autor(es): $\quad$ Sá, Alexandre Franco de \\ Publicado por: Imprensa da Universidade de Coimbra \\ URL \\ persistente: URI:http://hdl.handle.net/10316.2/38244 \\ DOI: $\quad$ DOI:http://dx.doi.org/10.14195/978-989-26-1049-8_10 \\ Accessed : $\quad$ 26-Apr-2023 14:44:30
}

A navegação consulta e descarregamento dos títulos inseridos nas Bibliotecas Digitais UC Digitalis, UC Pombalina e UC Impactum, pressupõem a aceitação plena e sem reservas dos Termos e Condições de Uso destas Bibliotecas Digitais, disponíveis em https://digitalis.uc.pt/pt-pt/termos.

Conforme exposto nos referidos Termos e Condições de Uso, o descarregamento de títulos de acesso restrito requer uma licença válida de autorização devendo o utilizador aceder ao(s) documento(s) a partir de um endereço de IP da instituição detentora da supramencionada licença.

Ao utilizador é apenas permitido o descarregamento para uso pessoal, pelo que o emprego do(s) título(s) descarregado(s) para outro fim, designadamente comercial, carece de autorização do respetivo autor ou editor da obra.

Na medida em que todas as obras da UC Digitalis se encontram protegidas pelo Código do Direito de Autor e Direitos Conexos e demais legislação aplicável, toda a cópia, parcial ou total, deste documento, nos casos em que é legalmente admitida, deverá conter ou fazer-se acompanhar por este aviso.

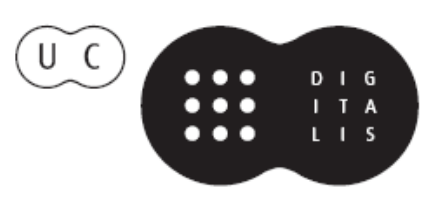



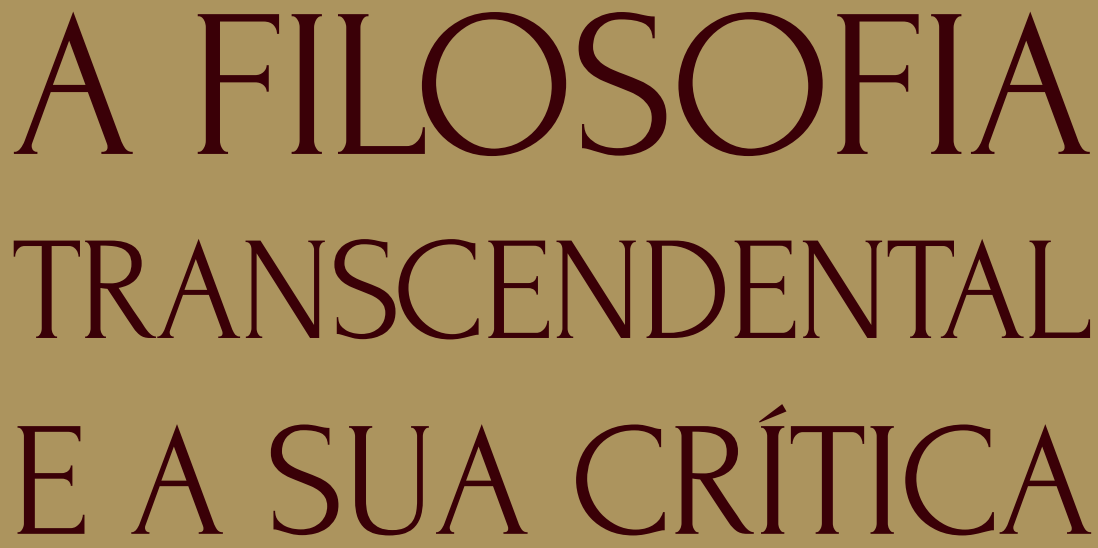

IDEALISMO • FenOMENOLOGIA • HERMENÊUTICA

\author{
DIOGO FERRER \\ LUCIANO UTTEICH \\ (COORDENADORES)
}




\section{A Abordagem Fenomenológica de Heidegger AO CONCEITO DE VIDA E O COMEÇO DA BIOPOLÍTICA HEIDEGGER'S PHENOMENOLOGICAL APPROAH TO THE CONCEPT OF LIFE AND THE BEGINNING OF BIOPOLITICS}

Alexandre Franco de Sá

(Universidade de Coimbra)

Abstract: Although Heidegger approaches the concept of life in some lectures and seminars, he never sufficiently clarifies life's status as a way of being in the framework of fundamental ontology. The present work is dedicated to this status. It argues that Heidegger's approach to the concept of life develops between the publication of Being and Time (1927) and the early Thirties, and that it must be considered in the context of Heidegger's relationship both with Ernst Jünger's thought and with National Socialism.

Keywords: Life, Fundamental Ontology, Animal, Human, Work

Resumo: Embora Heidegger aborde o conceito de vida nalgumas lições e seminários, ele nunca esclarece suficientemente o estatuto da vida como modo de ser no quadro da ontologia fundamental. O presente trabalho é dedicado a tal estatuto. Ele defende que a abordagem de Heidegger ao conceito de vida se desenvolve entre a publicação de Ser e Tempo (1927) e o início dos anos 
Trinta, e que ela tem de ser considerada no contexto da relação de Heidegger quer com o pensamento de Ernst Jünger quer com o Nacional Socialismo.

Palavras-Chave: Vida, Ontologia Fundamental, Animal, Humano, Trabalho

O capítulo que aqui apresentamos situa-se na linha de alguns estudos anteriormente realizados - dos quais resultaram algumas comunicações em encontros científicos e alguns artigos publica$\operatorname{dos}^{579}$ - e pretende reflectir sobre um movimento subtil que ocorre no pensamento de Heidegger ao longo da transição entre as décadas de 1920 e de 1930. Um tal movimento poderia ser caracterizado como um progressivo afastamento entre os modos de ser da existência e da vida, afastamento que possibilita, na sua conclusão, as conhecidas passagens da Carta sobre o "Humanismo" em que Heidegger afirma estar o homem separado do ser vivo por uma "distância essencial" que nem o "parentesco abissal" da sua partilhada situação corpórea consegue eliminar ${ }^{580}$. Sendo esse afastamento entre vida e existência um processo crescente no pensamento heideggeriano, inexplicável à luz daquilo a que poderíamos chamar o percurso imanente do projecto da ontologia fundamental, pretendemos aqui compreender o que está na sua base. Começaremos, portanto, por caracterizar a relação entre vida e existência no âmbito da ontologia fundamental para depois sugerir um modo de compreender a sua alteração.

Num primeiro momento, importa considerar que quando Heidegger estabelece o projecto de elaboração de uma ontologia fundamental (projecto esse que permaneceu, como se sabe, incompleto), o conceito de vida é explicitamente evocado como um modo de ser distinto do modo

${ }^{579}$ Cf. sobretudo Sá (2006); Sá (2007).

580 Cf. Heidegger (1976), 326. 
de ser do homem, mas de algum modo relacionado com ele. Depois de, ainda no início da década de 1920, se referir ao ser do homem como "vida fáctica", a qual deveria ser interpretada por uma hermenêutica de base fenomenológica, Heidegger elege o termo "existência" para assinalar o ser do homem, remetendo a vida para a designação de um modo de ser distinto do modo de ser humano. A vida passa, então, a designar estritamente o modo de ser dos animais não humanos. E é neste sentido que ela se caracteriza, enquanto modo de ser, através daquilo a que se poderia chamar uma constituição privativa. Segundo o Heidegger da ontologia fundamental, a vida é, enquanto modo de ser, uma privação ou uma subtracção: considerada apenas a partir da existência, isto é, a partir do modo de ser do homem, a vida é precisamente aquilo que no homem se subtrai à própria existência naquilo que ela tem de especificamente existencial ou humano. Como Heidegger afirma em Ser e Tempo:

"A vida é um tipo próprio de ser, mas essencialmente apenas acessível no Dasein. A ontologia da vida cumpre-se no caminho de uma interpretação privativa; ela determina aquilo que tem de haver para que possa haver algo como um mero viver". 581

Ao situar dessa forma o conceito de vida, Heidegger permite uma sua caracterização suficiente (embora meramente introdutória). Esta caracterização pode assentar aqui em duas notas. Por um lado, um tal conceito implica que toda a existência encerre em si a vida como elemento constitutivo. Por outro lado, este mesmo conceito implica que a vida só seja compreensível a partir da existência, enquanto vida despojada ou privada de existência. Neste sentido, por um lado, poder-se-á dizer que o homem é um animal e que a vida se encontra

581 Heidegger (1927), 50. 
nele como elemento constitutivo do seu ser. Por outro lado, ter-se-á de dizer que o animal não humano só é compreensível, no seu modo de ser específico, a partir da privação de humanidade que o caracteriza justamente enquanto não-humano. Noutros termos: segundo Heidegger, um animal não humano é o que é, na vida que o constitui enquanto seu modo de ser, por nele se subtrair a existência. É por isso que, como Heidegger afirma na conhecida passagem das suas lições de 1929-30, se a existência é ser-no-mundo, o animal é constituído não propriamente pela sua ausência de mundo, pela sua Weltlosigkeit (tal como a pedra é "carente de mundo" [weltlos]), mas antes por ser pobre de mundo [weltarm], ou seja, por um despojamento deste mesmo mundo. 582

As lições de 1929/30 acerca dos Conceitos Fundamentais da Metafísica são, então, a base para a consideração da relação que Heidegger estabelece entre vida e existência, entre o modo de ser do "animal" e o modo de ser do "homem". Ao estabelecer o animal não como carente, mas como apenas pobre de mundo, Heidegger caracteriza assim o animal (e Heidegger ignora aqui a especificidade do ser das plantas) através de uma analogia com o ser humano: do mesmo modo que o homem, o animal aparece como um ente marcado por um referir-se (Sichbeziehen) ou por uma abertura (Offenheit) ao ente. Contudo, o ente ao qual o animal se abre, longe de se lhe manifestar enquanto ente, apenas the aparece na medida em que corresponde, simultaneamente, ao estabelecimento de um determinado comportamento e à retirada de qualquer outra possibilidade. Nas lições de 1929/30, Heidegger assinala uma tal coincidência animal entre manifestação do ente e determinação do comportamento, ou seja, entre a possibilitação de um comportamento e a impossibilitação de todos os outros, através do verbo benehmen, o qual significa, como verbo reflexivo, comportar-se e, como verbo transitivo, tirar algo, arrebatar - como, por

582 Cf. Heidegger (1992), 263. 
exemplo, tirar a respiração (den Atem zu benehmen) ou tirar o apetite (den Appetit zu benehmen). A substantivação do particípio passado de um tal verbo - Benommenheit-, que significa um estado de confusão, de embriaguês ou de atordoamento, é usada aqui por Heidegger para justamente traduzir o comportamento animal na abertura a um ente que lhe arrebata qualquer outra possibilidade de comportamento. Na sua pobreza de mundo, a essência do animal consiste assim, para o Heidegger de 1929/30, neste comportar-se atordoadamente, ou seja, neste estar-arrebatado, nesta Benommenheit em relação ao ente, pela qual este mesmo ente, arrebatando-o, absorvendo-o, atordoando-o, lhe retira a abertura à sua própria manifestação como tal.

Diante da abertura do animal para um ente que aparece enquanto não manifesto, ou seja, que aparece não enquanto ente, mas enquanto arrebatador da possibilidade da sua manifestação como tal, a abertura humana ao mundo surge justamente determinada, na sua estrutura ontológica, pela possibilidade da manifestação. Nas lições de 1929/30, Heidegger elabora o tédio, a Langeweile, entendida como palavra composta que indica literalmente um durar longo do tempo, uma Lange-weile, como a afecção fundamental, a Grundstimmung, que propicia esta possibilidade. O tédio começa aqui, segundo a análise heideggeriana, na possibilidade de o ente ao qual o homem se encontra referido, por qualquer razão, faltar. Ao contrário do animal, o homem pode encontrar-se com o vazio aberto pela falta do ente, sendo este ficar vazio, esta Leergelassenheit, própria apenas da sua humanidade. Um tal deixar-se-estar-vazio, próprio do homem na sua relação com o ente, coloca-o em suspenso face ao próprio ente que falta, tornando-se num ser-deixado-em-suspenso, numa Hingehaltenheit. E tal ficar suspenso, próprio do homem na sua relação com o ente, mostra que o seu modo de ser consiste numa abertura não simplesmente ao ente, mas ao ente enquanto ente, ou seja, ao ente enquanto manifestação de um mundo, ao ente enquanto manifestação de um ser que, sendo a sua condição de possibilidade, não coincide com ele e aparece nele 
como estando encoberto. A abertura própria do homem, em contraste com a do animal, pode ser assim caracterizada como um dupla manifestação: por um lado, a manifestação do ente que esgota a abertura do animal; por outro, a manifestação do ser do ente, cuja abertura remete a abertura animal para um fechamento.

A leitura da vida, da abertura animal ao ente, como um fechamento, isto é, como uma privação ou subtracção da abertura humana ao ente enquanto ente e ao ser que a possibilita, permite compreender de que modo vida e existência se relacionam no plano da ontologia fundamental. A existência aparece como abertura de um fechamento originário. E a vida está contida na própria existência como o fechamento originário que pela abertura da existência é desencoberto. A partir desta relação entre vida e existência no plano da ontologia fundamental, o pensamento de Heidegger poderá desenvolver os dois conceitos essenciais de verdade e de mundo num plano que ultrapassa o seu tratamento em Ser e Tempo.

A determinação da verdade através do alpha privativo da $\alpha \lambda \eta \dot{\theta} \theta \varepsilon\llcorner\alpha$, a apresentação da verdade como uma "luta originária entre verdade e não-verdade", entre um $\lambda \dot{\eta} \theta \eta$ originário e a sua $\alpha \lambda \eta \dot{\eta} \theta \varepsilon\llcorner\alpha$, surgida a partir da conferência de 1930 "Sobre a Essência da Verdade", pode encontrar nesta interpretação da relação entre vida e existência o seu fundamento. Por um lado, a existência é, na sua abertura, um estar referido à verdade, um desencobrir. Por outro lado, se a vida se encontra no âmago da existência, e se a vida é fechamento, o desencobrimento que constitui a existência é sempre desencobrimento de um encobrimento originário. A luta originária, na verdade, entre encobrimento e desencobrimento corresponde assim a uma luta originária, no ser do homem enquanto existência, entre animalitas e humanitas. Giorgio Agamben, no seu livro O Aberto, tem razão ao interpretar a clareira, a Lichtung, como a abertura de um ser humano que encontra, no mais íntimo do seu ser, o fechamento próprio da vida animal. Como se pode ler claramente em O Aberto: “A jóia in- 
crustada no centro do mundo humano e da sua Lichtung não é senão o estar-arrebatado animal." 583

Para além do conceito de verdade, é também o desenvolvimento do conceito de mundo no pensamento de Heidegger que mais claramente mostra esta relação entre animalitas e humanitas na existência do homem. A existência é determinada no seu modo de ser, como se sabe, como ser-no-mundo. E é precisamente este mundo a que a existência se abre que começa a aparecer no pensamento heideggeriano, a partir da década de 1930, acompanhado da terra enquanto representante do fechamento que possibilita a abertura. Do mesmo modo que a abertura ocorre sempre a partir de um fechamento, que se abre nela apenas enquanto fechamento, assim a terra irrompe no mundo, emergindo nele enquanto terra fechada sobre si mesma. É esta relação intrínseca e originária entre mundo e terra que Heidegger torna patente em 1935, na conhecida reflexão em torno da Origem da Obra de Arte. Nesta obra, Heidegger fala da verdade como "luta originária", como Urstreit entre a abertura do mundo sobre a terra e o fechamento da terra sob o mundo:

"A terra só irrompe pelo mundo, o mundo só se funda na terra na medida em que a verdade acontece como combate originário de clareira e encobrimento". 584

É, então, diante das repercussões que a relação entre vida e existência tem nos próprios conceitos heideggerianos de verdade e de mundo que se torna inevitável perguntar pelas razões que levam Heidegger a abandonar a referência a esta mesma relação. Se o desenvolvimento dos conceitos de verdade e de mundo aponta para

583 Agamben (2002), 71.

584 Heidegger (1994), 42 [Usamos aqui a tradução de Irene Borges-Duarte e Filipa Pedroso: Heidegger (2002), 56]. 
uma relação entre existência e vida segundo a qual esta não pode deixar de ser considerada como um componente daquela, se a relação da verdade com um encobrimento originário, e do mundo com a terra, evocam a necessidade de pensar a existência humana como a abertura de um fechamento presente na abertura da vida animal ao mundo, que razão se pode encontrar para que Heidegger passe a aludir a uma "distância abissal" como separando a vida do animal e a existência enquanto modo de ser do homem? Como se explica que o pensamento de Heidegger se desenvolva no sentido da abertura de um abismo, de um Abgrund, entre o animal e o homem? Parece-nos que não é possível responder a esta questão sem considerar duas circunstâncias que marcam o pensamento heideggeriano a partir da década de 1930: em primeiro lugar, o encontro com o pensamento de Ernst Jünger, sobretudo com o seu livro O Trabalhador; em segundo lugar, a sua confrontação com o biologismo nacional-socialista.

Comecemos por abordar a primeira circunstância. Em O Trabalhador, livro que Heidegger trabalha sistematicamente logo após a sua publicação, em 1932, Jünger propõe-se pensar aquilo que considera como uma nova época que a Grande Guerra de 1914-18 teria tornado visível, uma era que seria caracterizada pelo despontar de uma realidade elementar à qual Jünger se refere com o nome que Nietzsche elege para a designar: a vontade de poder. Segundo Jünger, o século XIX poderia ser caracterizado como uma era burguesa e alienada, uma era humanista na qual a história seria vista como um progresso cumulativo e o homem - a sua liberdade e emancipação, o seu conforto e a sua segurança - seria considerado como o fim de todo o acontecer histórico. Para Jünger, colocando o progresso, a liberdade e o conforto do indivíduo humano como o seu destino, uma tal era burguesa perderia a noção de que no acontecer da história se desenrolaria uma potência não controlada humanamente, uma "vontade de poder" que se apropriaria do próprio homem e que não obedeceria senão a uma lei própria e imanente. Seria a realidade elementar desta lei que, 
segundo Jünger, poderia ser encontrada em fenómenos como a mobilização total da guerra, o automatismo do desenvolvimento técnico ou a transformação da paisagem planetária numa fábrica dinâmica construída sempre provisoriamente. E é à forma desta realidade elementar que Jünger chamará uma figura, uma Gestalt, que cunharia todos os fenómenos emergentes desta mesma realidade: a figura do trabalhador. Neste sentido, Jünger conceberá o homem do século XX já não como um indivíduo, actor e destino último da história, mas como uma figura tipo (Typus) cuja singularidade é cunhada pela figura do trabalhador. Segundo Jünger, numa realidade histórica em que o trabalho despontaria cada vez mais como realidade elementar, ao homem seriam dadas apenas duas possibilidades de relação com a figura do trabalhador: ou participar da figura do trabalhador, afirmando, com um realismo heróico, a mobilização total do mundo por esta mesma figura; ou negar esta mobilização, refugiando-se numa redoma romântica e alienada que o próprio processo de mobilização total, estendendo planetariamente a cunhagem da realidade pela figura do trabalhador, não poderia deixar de fatalmente destruir.

Se partirmos desta caracterização sumária das reflexões de Jünger em torno da figura do trabalhador, conjugando-a com a abordagem da relação heideggeriana entre vida e existência, concluiremos que a análise por Jünger da determinação do homem pela figura do trabalhador consiste na análise da redução das possibilidades abertas pela abertura humana ao ser a um carácter unidimensional, a um fechamento desta abertura e, nesta medida, ao carácter fechado de uma abertura que consiste num puro e simples arrebatamento pelo ente. No contexto da mobilização total do mundo por aquilo a que Jünger chama um "carácter total de trabalho" (totaler Arbeitscharakter), o homem é compreendido como estando arrebatado pela figura do trabalhador: ele torna-se agora um corpo animal ou, o que é o mesmo, uma mera vida arrebatada pela lei imanente a uma dinâmica elementar que irrompe nesta mesma figura. É assim que, em Jünger, a mobilização total aparece 
frequentemente ilustrada como uma mobilização do homem enquanto corpo. E os exemplos escolhidos por Jünger para esta caracterização não permitem sobre isso a menor reserva: o cultivo e modulação do corpo pelo exercício gímnico, a sua medição e regulamentação pela medicina, o seu cuidado através de políticas de saúde, a sua protecção por uma série de proibições legais, a sua padronização e embelezamento por cosméticos, a sua reabilitação por próteses, a sua uniformização pelo fardamento militar, profissional ou por um vestuário cada vez mais convencional e cosmopolita, a sua funcionalização como "força de trabalho", a sua utilização como kamikaze ou a sua instrumentalização como arma numa guerra que se torna, em consequência disso, uma "batalha de materiais", uma Materialschlacht.

Tais exemplos tornam claro que a mobilização total do mundo pela figura do trabalhador é caracterizável por aquilo a que Jünger chama uma "construção orgânica", uma organische Konstruktion. Nesta "construção orgânica", o homem já não se relacionaria com o mundo - como diria Heidegger - como um ente que se abre ao ser do ente, ou ao ente enquanto ente, mas como um ente afunilado num ente cuja manifestação the concentra toda a atenção e lhe arrebata a abertura de quaisquer outras possibilidades. Jünger caracteriza este arrebatamento sobretudo ao dizer que a técnica moderna, na qual a figura do trabalhador se cunha privilegiadamente, só obedece a uma lei própria, só tem imediatamente uma relação com a sua própria dinâmica, e não tem qualquer relação imediata com o homem ${ }^{585}$. Arrebatado pela lei própria e imanente desta técnica moderna, o homem torna-se ele mesmo uma "construção orgânica" mobilizável e, fundindo-se com o seu desempenho e com os seus instrumentos, torna-se ele mesmo redutível à vida simples do animal. Jünger é, acerca desta coincidência

585 Cf. Jünger (2000), 156, onde se afirma que "o homem não está ligado imediatamente, mas mediatamente, com a técnica. A técnica é a maneira em que a figura do trabalhador mobiliza o mundo". 
entre a fusão do homem com o desempenho técnico e a sua redução à vida animal, completamente explícito:

“Abordámos já o conceito de construção orgânica, que se manifesta, em relação ao tipo, como a estreita fusão, sem contradição, do homem com os instrumentos que estão à disposição dele. Em relação a estes instrumentos mesmos, pode-se falar de construção orgânica quando a técnica alcançar aquele mais elevado grau de evidência tal como o que habita dentro dos membros animais e vegetais". 586

Enquanto construção orgânica, a vida animal e vegetal surge aqui como o supremo grau de mobilização técnica. E se a vida surge como o modelo da construção orgânica que constitui o ponto culminante da mobilização técnica do mundo, como o modelo da exposição do mundo a uma vontade de poder totalmente mobilizadora, tal quer dizer que a vida é, para Jünger, a pura e simples exposição ao poder de uma mobilização total. Viver é, assim, estar exposto a (e arrebatado por) um poder que não permite qualquer resistência. E é esta constituição da vida como exposição a um poder mobilizador que, a partir do seu contacto com o pensamento jüngeriano, influencia profundamente o tratamento por Heidegger do próprio conceito de vida, marcando-o com um rumo distinto daquele que fora iniciado pelo seu tratamento ontológico-fundamental.

A partir da sua confrontação com Jünger, a vida surge, para Heidegger, já não como uma abertura limitada ao ente, a qual teria de ser compreendida privativamente - enquanto "apenas vida" - a partir de uma analogia com a existência, mas como a simples exposição e submissão de um ente a uma potência que simplesmente o arrebata e mobiliza. A partir da sua confrontação com o pensamento de Jünger,

586 Jünger (2000), 178. 
a vida animal surge, para Heidegger, não como algo apenas concebível a partir da existência, mas como a base para uma redução da existência à vida, ou seja, como a referência de um processo de mobilização pelo poder, e de exposição a uma potência elementar arrebatadora, cujo crescimento eliminaria simplesmente a existência enquanto modo de ser diferenciado. Por outras palavras, para Heidegger, a partir da leitura de Jünger, a vida deixa de ser um componente da existência, um fechamento que está sempre na base da abertura da existência, para passar a ser um elemento estranho que, estando contido nessa mesma existência, não poderia deixar de a corroer e destruir. É neste sentido que, para Heidegger, a cunhagem do homem pela figura do trabalhador, anunciada por Jünger, corresponderia a uma redução da existência à vida e, nesse sentido, a uma animalização do homem que eliminaria nele aquilo que seria propriamente humano.

Nas suas reflexões sobre Jünger, Heidegger é maximamente sensível a esta coincidência entre a mobilização total do mundo por um homem que assim se torna crescentemente o seu senhor, por um lado, e, por outro lado, a mobilização total do homem por um poder mobilizador que coincide com a sua escravização. Heidegger descreve aqui o trabalhador jüngeriano como, ao mesmo tempo, o sujeito e o objecto da mais extrema mobilização total do mundo, como um homem cunhado pela sua exposição ao mais extremo poder. É para a indicação dessa sua exposição ao poder que Heidegger o assinala já não como um homem ocidental propriamente dito, mas como um asiático, em cuja descrição é pensada a oposição clássica entre a liberdade grega e o despotismo oriental. A humanidade cunhada pela figura do trabalhador aparece aqui, aliás, intensificada no seu carácter estranho e asiático, sendo descrita como uma "chinesidade planetária" (planetarischer Chinesentum) ${ }^{587}$. Mas, pensado até ao fundo, um tal carácter configuraria mais que um aspecto estranho da humanidade. Esta humanidade tornada senhora de

${ }^{587}$ Heidegger (2004), 74, 174, etc.. 
um ente completamente mobilizado corresponde ao seu encerramento na mobilização desse mesmo ente, ou seja, à sua subordinação à mobilização deste mesmo ente que, na medida em que lhe arrebata quaisquer outras possibilidades de abertura, se torna marcado pelo abandono pelo ser. Na sua confrontação com Jünger, Heidegger escreve-o claramente: "Os 'senhores' são os escravos do abandono do ser do ente". 588 Se o trabalhador jüngeriano, o senhor do ente, é afinal o escravo do abandono do ser, tal quer dizer que este corresponde não propriamente a um aspecto humano stricto sensu, mas ao animal na sua abertura a um ente que lhe arrebata (e que, portanto, lhe encerra) toda a abertura possível. Assim, dir-se-ia que Heidegger teria de caminhar para a caracterização do trabalhador de Jünger como uma animalização do homem.

É justamente esta redução do homem à vida, esta redução do

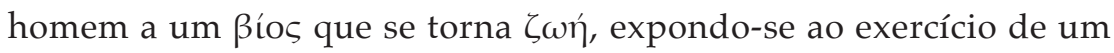
poder que o arrebata, que, por outro lado e numa abordagem do conceito de vida distinta da concepção jüngeriana, pode caracterizar o biologismo nacional-socialista como uma bio-política. Na Alemanha da década de 1920 e 1930, onde o conceito de biopolítica despontava, a experiência nacional-socialista surge, como mostrou Michel Foucault (e depois Roberto Esposito), como uma experiência essencialmente biopolítica caracterizada pela simultaneidade de dois processos entre si diferenciados: por um lado, a representação da população como um corpo orgânico, como vida vulnerável a doenças e a existências parasitárias, em relação às quais a sociedade se teria de defender, higienizar e imunizar; por outro lado, a exposição desta população como uma pura vida, como uma "vida nua" (no sentido colhido de Walter Benjamin por Giorgio Agamben), ou seja, como uma vida totalmente plástica, moldável e exposta à sua mobilização por um poder político que, justamente nessa medida, se torna essencialmente biopolítico. E é, então, também com a emergência do poder biopolítico nacional-

588 Heidegger (2004), 31. 
-socialista que o pensamento de Heidegger, ao abordar o tema da vida no contexto da década de 1930, não pode deixar de se confrontar.

No curso do pensamento que culmina na publicação da primeira parte de Ser e Tempo, em 1927, sobretudo ao longo do seu período de leccionação em Marburg, Heidegger tinha-se esforçado por construir as bases de uma ontologia fenomenológica, assente na rejeição do sujeito tradicional e na interpretação da existência como ser-no-mundo. A determinação do modo de ser do homem como ser-no-mundo trazia consigo a sugestão de uma sua interpretação como sempre já determinado ou destinado (no sentido da Bestimmung) pela sua situação, interpretação essa que não poderia deixar de apontar directamente para a concepção de um homem marcado, na sua essência, pela sua facticidade: o homem seria assim não um subjectum desvinculado, cuja liberdade originária surgiria como prévia e subjacente à sua situação no mundo, mas um ser-no-mundo já sempre determinado pelo seu estar-lançado nessa mesma situação. Seria, então, esta rejeição da concepção do homem como subjectum, esta determinação ou destinação do homem por uma situação fáctica, que, no contexto do despontar do nacional-socialismo na Alemanha, poderia ser facilmente interpretada de um modo biologista, numa interpretação que assentaria inevitavelmente na redução da facticidade da existência humana a simples vida animal, ou seja, na redução do homem a expressão singular de uma comunidade a cujo poder - convertido num poder omnipotente que tem a vida dessa mesma comunidade como objecto do seu exercício e protecção - se encontra totalmente exposto e submetido.

É sobretudo diante da possibilidade de uma interpretação biologista da sua analítica do existência como ser-no-mundo que, ao que nos parece, a separação heideggeriana da existência em relação à vida encontra a sua derradeira justificação. Neste sentido, é interessante verificar que é sobretudo na década de 1930, diante da emergência de uma concepção biologista do homem, que Heidegger, criticando dura e explicitamente o biologismo, começa a opor radicalmente os 
conceitos de vida e de existência. Nesta rejeição da vida como de algum modo relacionada com a existência, Heidegger continua a considerar esta mesma existência a partir da sua facticidade, a partir do estar-lançado no mundo. Mas este carácter de estar-lançado da existência configura-se, como Heidegger veementemente repete, não como uma redução do homem à condição de "mera vida", exposta e aberta à sua mobilização por um poder irresistível, mas como uma exposição do homem ao ente no seu ser, como uma exposição que arrebata o homem não para um fechamento, mas para uma abertura que se lhe manifesta como um acontecimento que o apropria, um Er-eignis.

É, contudo, não em conflito manifesto com o nacional-socialismo, mas sempre em confrontação pensante, aberta e persistente com o pensamento de Jünger, que Heidegger distingue entre aquilo a que se poderia chamar a "abertura aberta" da existência e a "abertura fechada" da vida, abertura essa que Heidegger atribui ao trabalhador jüngeriano, no seu arrebatamento pela potência elementar de uma "vontade de poder". Como indicação do conteúdo fundamental desta confrontação com o pensamento de Jünger, poderíamos assinalar uma pequena nota (a nota 73) das anotações de Heidegger sobre $O$ Trabalhador. Aqui, Heidegger aponta claramente para o fundamento da sua distinção entre vida e existência do seguinte modo:

“»Leben $"=$ sich in seiner Gestalt bestätigen.

Dagegen Menschsein:

Verwandlung in das Da-sein als der Gründung der Wahrheit des Seyns

"'Vida' = confirmar-se na sua figura

ser homem, pelo contrário:

transmutação no ser-aí enquanto fundação da verdade do Ser". 589

589 Heidegger (2004), 89. 
Dir-se-ia que, a partir de uma tal nota, o fundamento para a separação abissal entre o ser vivo e o humano fica, no pensamento de Heidegger, radicalmente estabelecido.

Por um lado, a vida surge aqui como a "confirmação" ou o "firmar-se" (a Bestätigung) de um ente na sua figura própria. Noutros termos, a vida é não um componente do indivíduo, mas a dimensão que nele o reduz a mera expressão singular da figura que o arrebata, da Gestalt que ocupa agora a sua própria essência. A partir desta configuração total do ente como figura, e usando os termos de Jünger, um tal ente - de que o ser vivo, enquanto construção orgânica, é a expressão privilegiada - já não é um indivíduo mas um tipo, ou seja, uma expressão singular da própria figura. Ele não pode, em nenhuma medida, contrapor-se, resistir ou sequer diferenciar-se da figura que o determina. Viver é, assim, confirmar esta mesma figura.

Por outro lado, diante da vida enquanto redução do indivíduo ao tipo e enquanto configuração do singular como figura, o homem deverá caracterizar-se sempre, enquanto existência, pela resistência a esta redução. Existir, ser homem, Menschsein é precisamente contrapor-se a esta "confirmação da Gestalt". Daí que ser homem implique o distanciamento de uma diferenciação de si próprio. Por outras palavras, ser homem implica uma transformação, uma Verwandlung, na qual já não é apenas uma abertura distinta da do animal que está em causa, mas um modo de ser radicalmente distinto: o ser o "aí" de uma Gründung, de uma fundação daquilo a que Heidegger chama não o ente, mas a Wahrheit des Seyns, a verdade do ser que sempre o ultrapassa e resiste ao seu arrebatamento.

Podemos, então, concluir: se o nacional-socialismo se tinha centrado numa biopolítica destinada a purificar a vida daquilo a que, nos seus próprios termos, se chamava Dasein ohne Leben, "existência sem vida", reduzindo o humano a uma vida purificada e cuidada biopoliticamente, dir-se-ia que a separação radical levada a cabo por Heidegger entre vida e existência, baseada numa repetida e 
profunda leitura de Ernst Jünger, encontra certamente uma das suas motivações de fundo na tentativa de resistir a esta redução biologista. Se a vida, na sua abertura limitada e arrebatada pelo ente, corrompia, enquanto elemento da abertura da existência, esta mesma existência, abrindo o campo para a redução nacional-socialista da existência à vida, a separação heideggeriana entre vida e existência só pode ser compreendida como uma tentativa de manter a própria existência na sua irredutibilidade e mistério.

\section{Bibliografia}

AGAMBEN, Giorgio (2002): L'aperto: l'uomo e l'animale. Turim, Bollati Boringhieri.

HEIDEGGER, Martin (1976): "Brief über den ,Humanismus". In: Wegmarken. Gesamtausgabe. Vol. 9, Frankfurt, Vittorio Klostermann.

HEIDEGGER, Martin (1927): Sein und Zeit. Tübingen, Max Niemeyer, 1986.

HeIDEGGER, Martin (1992): Die Grundbegriffe der Metaphysik: Welt - Endlichkeit Einsamkeit. Gesamtausgabe. Vols. 29-30, Frankfurt, Vittorio Klostermann.

HEIDEGGER, Martin (1994): “Der Ursprung des Kunstwerkes”. In: Holzwege. Frankfurt, Vittorio Klostermann.

HeIDEGGER, Martin (2002): “A origem da obra de arte". In: Caminhos de Floresta. Tradução de Irene Borges-Duarte e Filipa Pedroso, Lisboa, Gulbenkian.

HEIDEGGER, Martin (2004): Zu Ernst Jünger. Gesamtausgabe. Vol. 90, Frankfurt, Vittorio Klostermann, 2004.

JÜNGER, Ernst (2000): O Trabalhador: Domínio e Figura. Tradução de Alexandre Franco de Sá, Lisboa, Hugin.

SÁ, Alexandre Franco de (2006): “A Vida e o Humano em Heidegger: A Ontologia Heideggeriana na Aurora de uma Biopolítica". In: Pedro M. S. Alves - José Manuel Santos - Alexandre Franco de Sá (Eds.): Humano e Inumano: A Dignidade do Homem e os Novos Desafios. Actas do Segundo Congresso Internacional da Associação Portuguesa de Filosofia Fenomenológica - Universidade de Coimbra - Março de 2005. Lisboa, Centro de Filosofia da Universidade de Lisboa, pp. 353-363.

SÁ, Alexandre Franco de (2007): "Heidegger e o Fim do Mundo". In: Phainomenon 14. Lisboa, Centro de Filosofia da Universidade de Lisboa, pp. 241-253. 
